\title{
Temporary and Long-Term Consequences of Bereavement on Happiness
}

\author{
Nienke Moor ${ }^{1} \cdot$ Paul M. de Graaf ${ }^{1}$
}

Published online: 25 April 2015

(C) The Author(s) 2015. This article is published with open access at Springerlink.com

\begin{abstract}
In this article, we examine the temporary and long-term consequences of the death of a parent or child on happiness. According to set-point theory external conditions are expected to only have a short-term or limited influence on happiness. This directly contradicts the basic assumption of affective theories on happiness, which states that major life-events have a lasting influence on well-being. Moreover, we test whether the association between bereavement and happiness is equally strong across the life course. To test our hypotheses we make use of the fourth wave of the European Values Study. Our research findings demonstrate that people who lost their father, mother or child are more likely to feel unhappy than people without this experience. Ten years after the death of a parent or child we still find a significant difference in happiness between people who have and have not experienced this loss. The assumption of set-point theory, that major life evens only have a temporary impact on SWB, is not supported by our data. Moreover, the association between bereavement and SWB strongly differs across the life-course. We might even conclude that the age at which the loss occurred is more decisive for the strength of the association between bereavement and SWB than the duration of the loss.
\end{abstract}

Keywords Subjective well-being $\cdot$ Happiness $\cdot$ Bereavement $\cdot$ Death of parent $\cdot$ Death of child $\cdot$ Duration of loss

Nienke Moor

j.a.moor@tilburguniversity.edu

Paul M. de Graaf

PdeGraaf@tilburguniversity.edu

1 Department of Sociology, Tilburg School of Social and Behavioural Sciences, P.O. Box 90153,

5000 LE Tilburg, The Netherlands 


\section{Introduction}

A question that raises much debate in the literature is to what extent major life events have a lasting impact on the subjective well-being (SWB) of people. According to set-point theory, a person's SWB is a stable trait that depends largely on genetic disposition and personality traits (Brickman and Campbell 1971; Lykken and Tellegen 1996). From this perspective, major life events will affect a person's SWB on the short-term only. After a period of adaptation, people return to their set-points. However, recent literature questions this assertion (Fujita and Diener 2005; Lucas 2007; Clark et al. 2008; Heady 2010). Affective theories assume that SWB depends on the fulfilment of human needs, such as physiological needs, safety, respect, and affection (Veenhoven 2009). From this perspective, major life events are expected to have a more long-term impact on a person's SWB. In this article we aim to contribute to this discussion by examining the short-term and longterm consequences of the bereavement of close relatives on SWB. The death of a significant other is generally followed by a period of intense grief and suffering, leading to depressive disorder (Stroebe et al. 2007; Kersting et al. 2011). Although in most cases people recover from this depressive mood after the loss, it might be that their level of SWB will never be as high as before the loss.

A range of studies demonstrated that the death of one's spouse is among the most stressful life-events that people encounter in their lives (Stroebe et al. 2007). Because of grief, emotional strain, and also because of the loss of social and economic resources, losing one's partner at least temporarily lowers mental and physical well-being (Kalpakjian et al. 2011; Specht et al. 2011; Luhmann et al. 2012). Panel studies show that the death of the spouse has a huge impact on people's SWB, but that widowed people in general manage to recover to their base level of SWB after 5-7 years (Lucas et al. 2003; Clark et al. 2008). In their review of studies on the relationship between people's health and the loss of a relative, Stroebe et al. (2007) concluded that most studies on the consequences of bereavement focus on spousal bereavement. Only a limited range of studies examined the consequences of the loss of other significant relatives for well-being (Ballas and Dorling 2007; Oswald and Powdthavee 2008; Rostila and Saarela 2011). In this study we will focus on the temporary and long-term consequences of the death of a parent or a child on SWB.

Given the fact that experiencing the death of a parent is a common life-event, it may not be surprising that there has been so little research to its consequences for SWB in adult life (Marks et al. 2007; Pudrovska 2009). However, it is clear that, although the importance of parental ties may diminish when people start having a family of their own, parents still have a very significant impact on the lives of their adult children by both giving and receiving emotional, practical and financial support. Therefore, it may be expected that the death of one's father or mother affects SWB, although it seems likely that the negative impact will disappear after some time.

Losing a child is considered to be more detrimental to people's physical and mental health than losing a partner or parent. When comparing different kinds of adult bereavement, grief reactions proved to be most intense for bereaved parents (Sanders 1979; Middleton et al. 1998). Losing a child is so devastating that it can increase the risk of psychiatric hospitalization and mortality in the grieving parent ( $\mathrm{Li}$ et al. 2003, 2005; Rostila et al. 2012). The love of parents for their children is uniquely strong and enduring, as children give meaning and a sense of purpose to their parents' lives. Since children in general outlive their parents, losing a child is much more uncommon and unexpected than 
losing a parent or partner (Rostila and Saarela 2011). This 'off-time' event in a life course probably will have more severe consequences for SWB (Pudrovska 2009).

In this study we aim to examine the association between bereavement and happiness by contributing to the literature in three ways. First, we will assess both short-term and longterm consequences of bereavement for SWB to test the concept of 'lasting grief'. As we have data about the time elapsed since the death of a parent or child we will study to what extent the difference in SWB between people who have and who have not lost a child or parent decreases with the duration of the loss.

Second, we contribute to the literature by using a life course perspective. Although bereavement in general will be negatively associated with well-being, it is not sure whether this association is equally strong across the life course. It can be argued for example that the negative impact of parental death on the happiness of adult children declines over the life-course, as parental death becomes more natural and expected with the age of the parent (Rostila and Saarela 2011). For testing these types of hypotheses, we take into account the age of the respondent at the time of the loss.

Third, we will test whether the association between bereavement and SWB differs between men and women. The literature suggests that individuals react differently to external events and afterwards differ in their level of adaptation (Lucas et al. 2003; Diener et al. 2006). It may be that women are better able to cope with bereavement than men because on average they have a larger social network and therefore are more likely to receive emotional support from family and friends. It may also be that women are more vulnerable to grief because often they are more closely involved with their parents and children than men are.

As we do not have panel data at our disposal we cannot perform a direct test of set-point theory. In contrast to the study by Oswald and Powdthavee (2008), we are not able to examine to what extent people return to their set-points after the death of their parent or child. However, because of the use of the cross-sectional dataset European Values Studies we can test our hypotheses about the relationship between bereavement and SWB on the basis of a large sample. Previous studies demonstrated that the death of a child is related to depressive symptoms and poorer health, but the sample of bereaved parents in most of these studies is relatively small (Oswald and Powdthavee 2008; Rogers et al. 2008; Song et al. 2010; Kersting et al. 2011). The large size of the European Values Studies enables us to study the effect of bereavement in interaction with the age at which the loss occurred and the time elapsed since the death of the parent or child.

Our overarching research question then reads: To what extent is there a relationship between bereavement and SWB, and how does it differ (a) with the duration of the loss, (b) across the life-course, and (c) between men and women.

\section{Theory and Hypotheses}

Depression is considered to be a normal response to bereavement, especially early on in the grieving process. In the literature, different phases or tasks of grieving are distinguished that describe the normal course of the grieving process (Stroebe et al. 2007). Over time, most bereaved people prove to be resilient, although there are large individual differences in the rate at which people adjust (Boerner et al. 2005). In the case that grief becomes chronic and more intense this is labelled complicated grief (Middleton et al. 1996). 
Although from a clinical perspective, most people recover from their loss with time, the question remains to what extent bereavement affects their overall well-being. Does the death of a parent or child have a lasting impact on SWB? When we consider the literature on this topic, we recognize contradicting theoretical traditions (Veenhoven 2009). Setpoint theory, a dominant theory in research on SWB, assumes that people have a fixed 'setpoint' around which well-being fluctuates (Brickman and Campbell 1971; Lykken and Tellegen 1996). External conditions are expected to only have a short-term and limited influence on SWB. This assumption of set-point theory directly contradicts the more affective theoretical perspective on SWB, which states that happiness is determined by the extent people are able to fulfil their material and social human needs to have a satisfying life. From this perspective, external resources, as long as they are related to basic human needs, can have a long-term impact on SWB.

\subsection{Short-Term and Long-Term Consequences of Bereavement on SWB}

Due to rehearsed revisions and extensions on previous theory, set-point theory was developed by different scholars under different labels (Heady 2010). The basic assumption is always that people's SWB in adult life hardly changes, except temporarily in the case of major life events. Happiness is considered to be a stable trait, as it is argued to depend largely on genetic disposition (Lykken 1999) and personality traits (Costa and McCrae 1980; Heady and Wearing 1989, 1992). This is well illustrated by the following quote: "Taken to the extreme, set-point theory would predict that we are equally happy in Heaven as in Hell" (Veenhoven 2009: p. 54). People will be equally happy during their life course, apart from some minor fluctuation due to major life events. However, irrespective of the event, the psychological balance is expected to be restored after a few years. Thus, our setpoint hypothesis reads: The death of a parent or child has a temporary effect on people's feelings of happiness (H1a).

Nonetheless, a growing number of studies demonstrate that some life events have a long-term influence on SWB. This is suggested to be especially the case for negative life events in comparison to positive life events (Baumeister 2002), and especially for life events within the domain of family and health (Easterlin 2005). Long-term unemployment as well as transitions into and out of marriage and parenthood appear to have a lasting influence on SWB (Clark et al. 2008; Waite et al. 2009; Umberson et al. 2010).

In contrast to set-point theory, affective theories of well-being do not consider happiness to be a constant (Veenhoven 2009). Happiness reflects people's state of mind and therefore depends on both positive and negative experiences (Diener et al. 1991). An important assumption of this theoretical perspective is that people are happier when their basic needs are fulfilled. This is illustrated by the finding that people who live in countries with more favourable circumstances are in general happier (Veenhoven 1994). Besides material and personal resources, social resources can be considered part of basic human needs (Diener and Fujita 1995). Because they provide affection, support and social integration, the absence or loss of social resources can be threatening people's well-being (Lindenberg 1986; Ormel et al. 1999). Family relationships are one of the most intimate and long-term relationships that people engage in during their lives. Especially the ties with parents and children are close and cannot easily be replaced once lost. From this resources perspective, we derive our resources hypothesis: The death of a parent or child has a long-term effect on people's feelings of happiness (H1b). 


\subsection{The Consequences of Bereavement During the Life Course}

Parental death is argued to excite depressive feelings, not only because of mourning, but also because of a lack of care provided by significant others (Bifulco et al. 1992). Losing one's parent in childhood and losing one's parent in adult life is both associated with depression and reduced well-being in adult life (Maier and Lachman 2000; Ballas and Dorling 2007; Oswald and Powdthavee 2008; Mandemakers 2011). On the basis of the resources perspective we expect the impact of parental death on SWB to differ across the life course. Research findings reveal a steep decline of support given by parents to their adult children, as parents get older. The support given to parents also gradually declines during the life course, but shows an upturn again when parents are over 80 years of age (Rossi and Rossi 1990). Similarly, Cooney and Uhlenberg (1992) found that after having received a substantial amount of support from their parents in their $20 \mathrm{~s}$, there is a decline in all forms of support received from parents after age 30. Given the decreasing dependence on parents for support and the increased need to provide support to elderly parents, we expect the impact of parental death on SWB to diminish in adult life.

Moreover, it can be argued that experiencing parental death in adult life is less traumatic for people than experiencing the death of a parent in childhood or young adulthood. With the age of the adult child, parental death becomes more natural an expected (Rostila and Saarela 2011). As most children outlive their parents, parental death is a natural life course transition in adult life (Marks et al. 2007). When parents die in old age, parental death can even evoke feelings of relief in the adult child. Family members who provide end-of-life care to their parent experience high levels of physical and psychological strain for a longer period of time (Pinquart and Sörensen 2007; Schulz and Sherwood 2008). In the case of a seriously ill parent, death puts an end to the suffering of the parent and a period of high stress for the adult child (Schulz et al. 2003). The feeling of 'it's better this way' may dominate.

On the basis of the above mentioned reasoning we come to our life span hypothesis: The negative impact of parental death on SWB will decline with the age of the child on the moment the parent died (H2).

With regard to the impact of the death of a child on happiness, it is difficult to formulate a life course hypothesis. As stated by Pudrovska (2009), the death of a child is against 'natural law', as children are expected to outlive their parents. From this perspective, losing a newborn or a young child is the same as losing an adult child. However, it is possible that losing a child in pregnancy or directly after birth is less traumatic for parents than losing an adult child, because they had less opportunity to develop a strong emotional bond. It was indeed found that short-time reactions were less severe for parent whose child died in infancy compared with parents whose child died in adult life (Wijngaards-de Meij et al. 2005), but it not known whether these reactions remain intact over a longer period.

\subsection{Gender Differences in the Impact of Bereavement on SWB}

Studies which have examined the consequences of bereavement for well-being often took into account possible gender differences. In most of these studies it has been found that mothers have more short-time emotional problems after the death of their child as compared to men (Li et al. 2003; Wijngaards-de Meij et al. 2005; Oswald and Powdthavee 2008; Kersting et al. 2011). However, a recent study by Pudrovska (2009) has a different conclusion: fathers are more negatively affected by the death of their child than mothers. In 
the case of parental death, it was found that sons, in terms of mortality risks and physical health, are more vulnerable following the death of a parent than daughters are (Marks et al. 2007; Rostila and Saarela 2011).

From a gender role perspective, it can be argued that men and women respond differently to the death of a family member, considering the existing gender roles within society. Traditionally there are feminine and masculine gender roles, in which women have the role of caretaker and men have the role of provider. In other words, men are socialized to be productive members of the work domain, whereas women are socialized to be productive members of the family domain (Bielby and Bielby 1988). However, in modern society traditional gender roles have become less strict. It has become more common for women to have a career, whereas men are increasingly expected to participate in household and child caring tasks. Although feminine and masculine gender roles intertwine, a majority of women still put more effort in the family role than in the work role, whereas the reverse is true for men (Gutek et al. 1991). The male gender role as financial provider continues to be important in contemporary society (Loscocco and Spitze 2007), whereas the combination of the family role and the work role is characteristic for the social position of most women nowadays. Women, in general, have more direct contact with their family members than men and are often responsible for the care of their young children and old parents (Rosenthal 1985; Craig 2006; Wall and Arnold 2007).

On the basis of this gender role perspective, we argue that the family domain is more salient in the feminine gender role, whereas the work domain is more salient in the masculine gender role. Note, that we explicitly do not claim that family is not an important part of men's lives. We only state that the role of family caretaker, in comparison with other social roles, is more pronounced in the identity of women than in that of men. From this perspective, we expect women to have stronger grief reactions following the death of their parent or child than men, as they are more responsive to life events that relate to the domain of the family. However, in the case of a seriously ill parent, this can be the other way around, as women more often are released from caregiver stress and feel more relieved that their parent no longer suffers. Nonetheless, in general, our gender role hypothesis reads: The negative impact of the death of a parent or child on SWB is stronger for women than for men (H3a).

In contrast to the gender role hypothesis, it can be argued that women, and not men, are better able to cope with the death of a relative. In the case of dealing with stressful lifeevents, women appear to have better coping skills than men and also have a larger social network on which they can rely for emotional support (Stroebe and Stroebe 1983; Umberson et al. 1996; Stroebe 2001). In this respect, it is demonstrated that women are better able to cope with the loss of their partner through widowhood than men are (Umberson et al. 1992; Stroebe et al. 2007). Our emotional coping hypothesis reads: The negative impact of the death of a parent or child on SWB is weaker for women than for men (H3b).

In studying the relationship between bereavement and SWB, it is important to take into account the gender of both the grieving person and the deceased person (Rostila and Saarela 2011). In this study, we can make a distinction between the impact of the death of the father and the death of the mother on people's happiness. From the gender role perspective, it can be argued that the death of the mother has a stronger impact on adult children's well-being than the death of the father. Mothers are the primary attachment figure for young children, but also in adult life mother-child relationships are characterized by more affective and emotional closeness than father-child relationships (Rossi and Rossi 1990). From this we derive the following hypothesis: The death of the mother will have a stronger influence on the happiness of adult children than the death of the father $(\mathrm{H} 3 \mathrm{c})$. 
Although in the literature the importance of the mother for the well-being of children is often emphasized, it is also suggested that the death of the same-sex parent has the strongest influence on the well-being of their offspring (Marks et al. 2007). From an early age, children will identify most with their same-sex parent and hence feel a stronger emotional bond with this parent, also in adult life. Thus, we derive our same-sex parent hypothesis: The death of the mother has a stronger influence on the happiness of women, whereas the death of the father has a stronger influence on the happiness of men (H3d).

In the same way, we can hypothesize that the death of daughter would have stronger effects on the happiness of women than on the happiness of men, and vice versa. However, our data does not offer information on the sex of deceased children.

\section{Data and Measurements}

To test our hypotheses, we make use of the fourth wave of the European Values Study (2008), which covered 47 European countries/regions (EVS 2010). The European Values Study is a large-scale repeated cross-sectional study, with earlier waves in 1981, 1990 and 1999. In each country a random sample of 1500 persons were interviewed. The interviewers were conducted face-to-face by interviewers trained for this purpose. In the questionnaire, adult respondents were asked questions around central themes of human life: family, religion and morality, politics, work and leisure. We use the European Values study because it contains data about the age at which a respondent has experienced the death of a father, mother, or child. Moreover, because of the large sample size, we are able to study the effect of bereavement in interaction with the age at which the event occurred and the duration since the event occurred. In our research we use data for forty-six European countries. Because of the seemingly non-representative sample of Azerbaijan, we excluded this country from our analysis.

In examining the consequences of bereavement on SWB, we performed two different analyses. In our first analysis we focus on the relationship between parental death and SWB. Because we wanted to exclude the group of respondents who are likely to have lost both their parents, we selected respondents aged 60 years or younger. In our second analysis we examine the relationship between the death of a child and SWB. Here, we only selected respondents who have (had) at least one child. In this way we can compare parents who have lost a child with parents who have not lost a child.

\subsection{Measurements}

We measure our dependent variable SWB with the four-point scale 'taking all things together, would you say you are: very happy, quite happy, not very happy, or not at all happy'. With this simple scale, people's SWB is measured as well or even better than with more complex measurements of well-being (Veenhoven 1993). We decided to use the happiness scale over the life satisfaction scale (which is also available in the EVS), because the first scale is demonstrated to have a more affective character as compared to the more cognitive character of the life satisfaction scale (Diener et al. 2002). We recoded the variable into a dichotomous one in which respondents who are unhappy (not very happy or not at all happy) receive score 1.

With regard to parental death, or the death of a child, respondents were asked the following question: Have you ever experienced any of the following events? If yes, at what age? Subsequently, we constructed for each type of loss three variables. The first variable 
Table 1 Frequency distributions of the bereavement variables

\begin{tabular}{|c|c|c|c|c|c|c|}
\hline & $<2$ & $3-5$ & $6-10$ & $>10$ & Recent ( $\leq 5$ years ago) & Not recent $(>5$ years ago) \\
\hline \multicolumn{7}{|c|}{ Years since death father } \\
\hline \multicolumn{7}{|c|}{ Age at death father } \\
\hline$<21$ year & 66 & 112 & 275 & 3090 & 178 & 3365 \\
\hline $22-40$ year & 529 & 776 & 1380 & 4565 & 1305 & 5942 \\
\hline$>40$ year & 948 & 1071 & 1362 & 886 & 2019 & 2248 \\
\hline Total & 1543 & 1959 & 3017 & 8541 & 3502 & 11,558 \\
\hline \multicolumn{7}{|c|}{ Years since death mother } \\
\hline \multicolumn{7}{|c|}{ Age at death mother } \\
\hline$<21$ year & 22 & 41 & 84 & 1151 & 63 & 1235 \\
\hline $22-40$ year & 259 & 391 & 676 & 2250 & 650 & 2926 \\
\hline$>40$ year & 983 & 1052 & 1272 & 716 & 2035 & 1988 \\
\hline Total & 1264 & 1484 & 2032 & 4117 & 2748 & 6149 \\
\hline \multicolumn{7}{|c|}{ Years since death child } \\
\hline \multicolumn{7}{|c|}{ Age at death child } \\
\hline$\leq 40$ year & 53 & 58 & 104 & 1408 & 111 & 1512 \\
\hline$>40$ year & 152 & 177 & 226 & 493 & 329 & 719 \\
\hline Total & 205 & 235 & 330 & 1901 & 440 & 2231 \\
\hline
\end{tabular}

Source: European Values Study 2008

is a dichotomous one, which indicates whether or not respondents ever experienced the death of their father, mother, or child. The second variable refers to the duration of the loss and has five categories: (1) the father/mother is alive, (2) $\leq 2$ years, (3) between 3 and 5 years, (4) between 6 and 10 years, (5) over 10 years. Because the number of people who (recently) lost a child is limited, we constructed just four answer categories: (1) not experienced the death of a child, (2) $\leq 5$ years, (3) between 6 and 10 years, (4) over 10 years. The third variable refers to the age at which the loss occurred. For parental death, we distinguish between four categories: (1) the father/mother is alive, (2) experienced in youth $(<21$ years), (3) experienced at an age between 22 and 40 years, (4) experienced at an age over 40 . For the death of a child, the second category 'in youth' is not applicable. Finally, we constructed a variable for each type of loss that combines the answer categories from the duration variable and the age of loss variable. When the death of a parent or child took place 5 years ago or less we see it as recent loss. The frequency distributions of the bereavement variables can be found in Table 1 .

Please note that in the case of the death of a child respondents were asked about the age at which they lost a child for the first time. As a consequence, the results for people who have lost more than one child can be somewhat distorted. However, we do not consider this a major problem as losing more than one child is a rare occurrence.

In studying the relationship between bereavement and SWB we take into account several control variables on the individual level to minimize the possibility of a spurious relationship ${ }^{1}$

\footnotetext{
1 Apart from social factors, genetic factors can precede both the likelihood of bereavement and SWB. Because we have no information about genetic factors, we cannot test this possibility. However, it seems unlikely that the association between bereavement and SWB can be largely attributed to genetic vulnerability to poor mental health.
} 
As a first control variable we include the age of the respondent. In general, older people report lower levels of happiness than younger people, whereas the likelihood to experience the death of a family member (especially a parent) increases with age. Since these relationships are probably not strictly linear, we decided to distinguish between seven age groups: (1) <30 years, (2) 31-40 years, (3) 41-50 years, (4) 51-60 years, (5) 61-70 years, (6) $71-80$ years, (7) $>80$ years.

In our analysis on the association between parental death and SWB we also control for the socioeconomic status of the family of origin. People who have grown up in lower-class families in general have lower levels of SWB and, due to selective mortality, are also more likely to lose their parents at a relatively young age. We take into account the highest completed level of education of the father. We distinguish between three categories based on the International Standard Classification of Education (ISCED): low (ISCED 0, 1, 2), middle (ISCED 3, 4), and high (ISCED 5, 6). Moreover, we control for the occupational status of the father on the basis of the International Socioeconomic Index (ISEI) that ranges from 16 to 90 . This ordinal scale measures occupational prestige and is derived from the educational level and income level of employees in different occupations (Ganzeboom et al. 1992). When respondents did not live with their father on the age of 14 , the educational level and occupational status of the mother are used to measure socioeconomic status. Financial security in people's youth is measured by asking respondents to what extent their parents had problems making ends meet. This variable ranges from 0 to 3 , with a higher score indicating more financial security in people's youth.

In our analysis on the association between the death of a child and happiness we control for people's own socioeconomic status, as people from lower socioeconomic classes in general have lower levels of SWB and are more likely to lose a child or parent due to illness or an accident. We take into account people's monthly household income in the different countries, which are made comparable by using Purchasing Power Parity exchange rates. People's highest completed level of education is measured by converting country-specific codes for educational level into three categories on the basis of the International Standard Classification of Education (ISCED): low (ISCED 0, 1, 2), middle (ISCED 3, 4), and high (ISCED 5, 6). We measure people's occupational status by using the ISEI-index that ranges from 16 to 90 . People who are currently unemployed or retired but had paid employment before receive the ISEI-score of their latest job. People who never had a paid job and who are married/cohabiting receive the ISEI-score of their partner.

To test whether the association between bereavement and happiness is different for men and women we also include the dichotomous variable woman in our models.

For our categorical independent variables, we created separate dummy-categories for the missing values (except for the variables age and gender). The missing values on the bereavement variables that refer to the age at which one experienced the loss are relatively high, as respondents who experienced the death of their parent or child did not always report the age at which this happened. For these cases we are not able to estimate the interaction effects of bereavement on the one side and age of event and duration on the other side. For the continuous variables financial security in youth, household income and occupational status, we created a binary indicator variable that is coded 1 if the value is missing. Subsequently, the people with missing values were assigned the country mean for the specific variable. Table 2 presents the descriptive statistics of the variables used in our analyses. 
Table 2 Descriptive statistics

Mean (\%)

Analysis 1: parental death-happiness

Unhappy (0-1)

$14.8 \%$

Death father (0-1)

$34.4 \%$

Death father-missing (0-1)

$0.3 \%$

Duration of death father

Not experienced (0-1)

$65.3 \%$

$0-2$ years ago $(0-1)$

$3.1 \%$

$3-5$ years ago $(0-1)$

$3.9 \%$

6-10 years ago $(0-1)$

$6.0 \%$

$>10$ years ago $(0-1)$

$16.5 \%$

Missing (0-1)

Age $\mathrm{R}$ at death father

Not experienced (0-1)

$65.3 \%$

$<21$ year (0-1)

$7.2 \%$

22-40 year $(0-1)$

$14.4 \%$

$>40$ year $(0-1)$

$8.0 \%$

Missing (0-1)

$5.1 \%$

Death mother (0-1)

$20.5 \%$

Death mother-missing (0-1)

$0.1 \%$

Duration of death mother

Not experienced (0-1)

$79.4 \%$

$0-2$ years ago $(0-1)$

$2.5 \%$

$3-5$ years ago $(0-1)$

$2.9 \%$

6-10 years ago $(0-1)$

$3.9 \%$

$>10$ years ago $(0-1)$

$7.9 \%$

Missing (0-1)

$3.4 \%$

Age $\mathrm{R}$ at death mother

Not experienced (0-1)

$79.4 \%$

$<21$ year (0-1)

$2.6 \%$

22-40 year $(0-1)$

$7.1 \%$

$>40$ year $(0-1)$

$7.5 \%$

Missing (0-1)

$3.4 \%$

Woman (0-1)

$50.3 \%$

Age (18-60)

Education father

Low (0-1)

$44.6 \%$

Middle (0-1)

$34.2 \%$

High (0-1)

$13.5 \%$

Missing (0-1)

$7.7 \%$

38.85

ISEI father (16-90)

$18.8 \%$

ISEI father-missing (0-1)

1.79

1.10

Financial security youth $(0-3)$
Financial security-missing $(0-1)$

$6.6 \%$ 
Table 2 continued

\begin{tabular}{|c|c|c|}
\hline & Mean $(\%)$ & SD \\
\hline \multicolumn{3}{|c|}{ Analysis 2: death of a child-happiness } \\
\hline Unhappy (0-1) & $18.3 \%$ & \\
\hline Death child (0-1) & $6.6 \%$ & \\
\hline Death child - missing $(0-1)$ & $0.1 \%$ & \\
\hline \multicolumn{3}{|l|}{ Duration of death child } \\
\hline Not experienced $(0-1)$ & $93.3 \%$ & \\
\hline$<5$ years ago $(0-1)$ & $0.9 \%$ & \\
\hline $6-10$ years ago $(0-1)$ & $0.7 \%$ & \\
\hline$>10$ years ago $(0-1)$ & $4.0 \%$ & \\
\hline Missing (0-1) & $1.1 \%$ & \\
\hline \multicolumn{3}{|l|}{ Age $\mathrm{R}$ at death child } \\
\hline Not experienced $(0-1)$ & $93.3 \%$ & \\
\hline$<40(0-1)$ & $3.4 \%$ & \\
\hline$>40(0-1)$ & $2.2 \%$ & \\
\hline Missing $(0-1)$ & $1.1 \%$ & \\
\hline Woman $(0-1)$ & $55.5 \%$ & \\
\hline Age (16-108) & 51.14 & 15.55 \\
\hline \multicolumn{3}{|l|}{ Educational level } \\
\hline Low $(0-1)$ & $33.7 \%$ & \\
\hline Middle (0-1) & $44.5 \%$ & \\
\hline High $(0-1)$ & $21.8 \%$ & \\
\hline Income (0-14.3) & 1.25 & 1.30 \\
\hline Income-missing $(0-1)$ & $15.8 \%$ & \\
\hline ISEI (16-90) & 42.24 & 16.76 \\
\hline ISEI-missing $(0-1)$ & $7.8 \%$ & \\
\hline
\end{tabular}

Source: European Values Study 2008

\section{Results}

In order to answer our research question, we performed logistic regression analysis ${ }^{2}$

To control for the main effects of country, we computed fixed effects models in which we include the different countries as dummy-variables. Positive logits in our models can be associated with an increased probability of feeling unhappy. In our first analysis we examine to what extent the death of a father or mother is related to happiness. This analysis is based on 48,829 respondents younger than 60 years. Our second analysis that focuses on the association between the death of a child and happiness is based on the 45,686 respondents who at least have (had) one child. In both analyses, we take into account the duration of the loss as well as the age at which the loss occurred. Finally, we include

\footnotetext{
${ }^{2}$ As happiness is an ordinal variable which is also highly skewed, linear regression analysis is not appropriate here. Therefore, we decided to recode happiness into a dichotomous variable in order to be able to perform logistic regression analysis. We additionally performed ordered logit regression analysis. The results of this analysis are not that different from the results of the logistic regression analysis as presented in this study.
} 


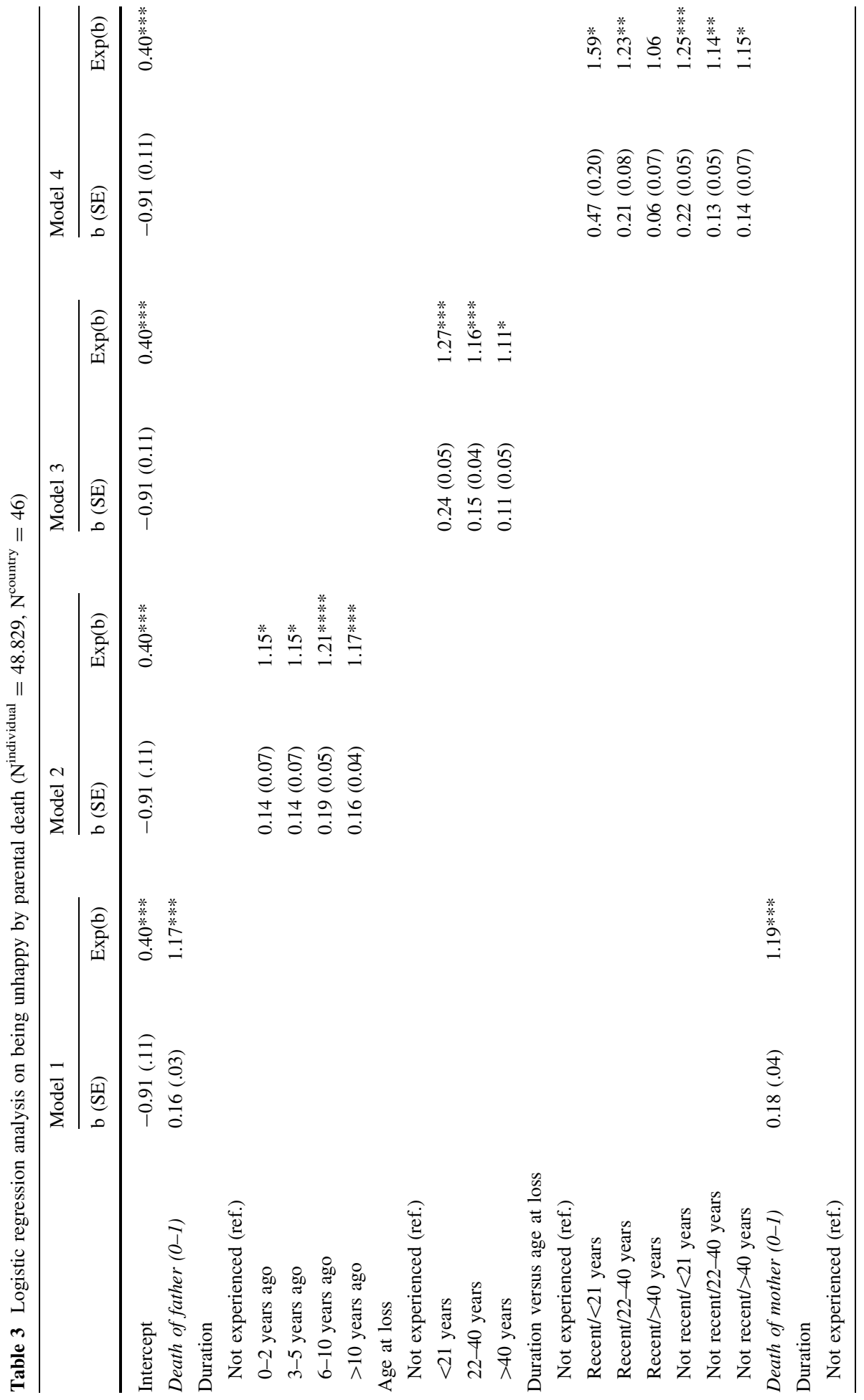




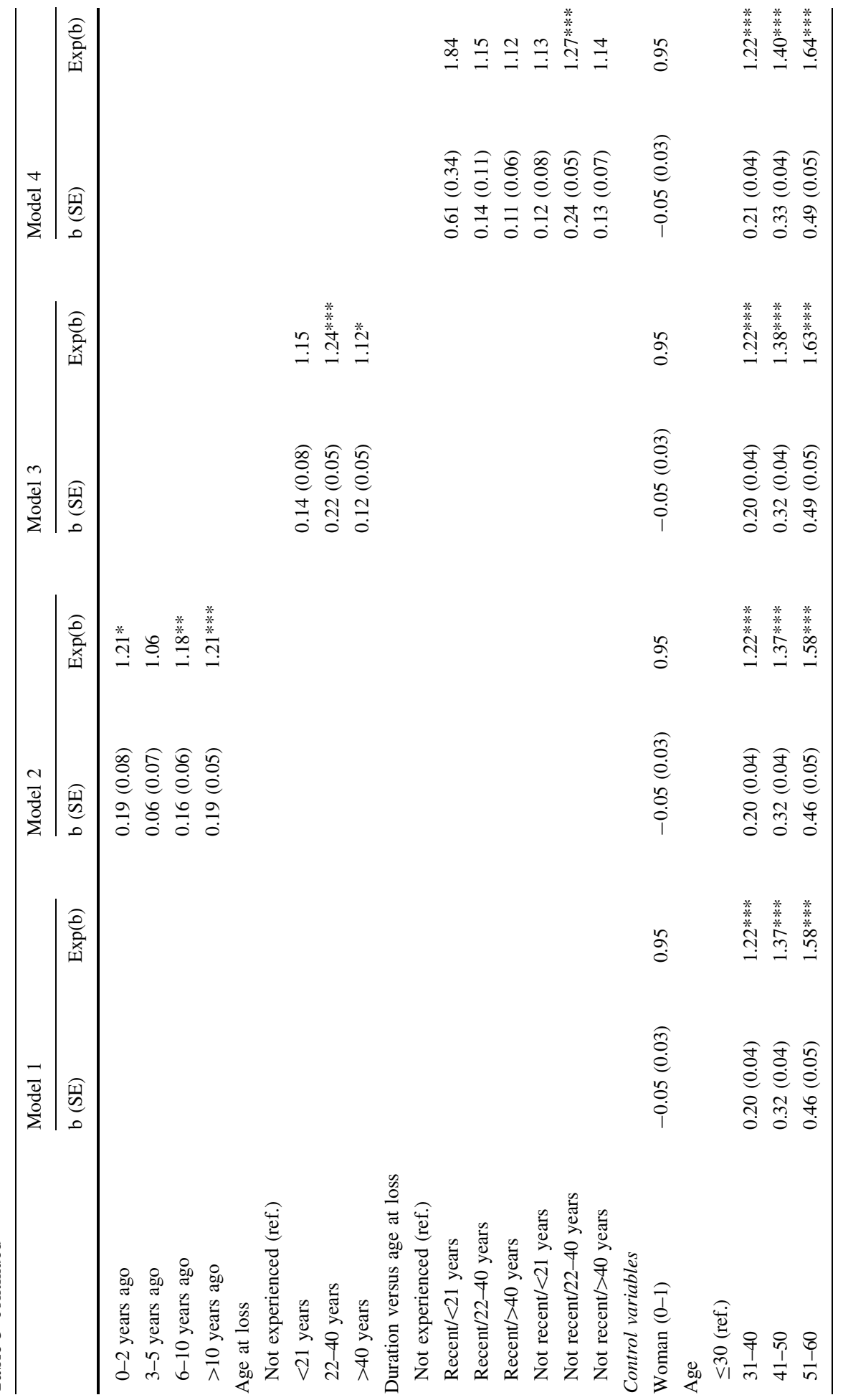




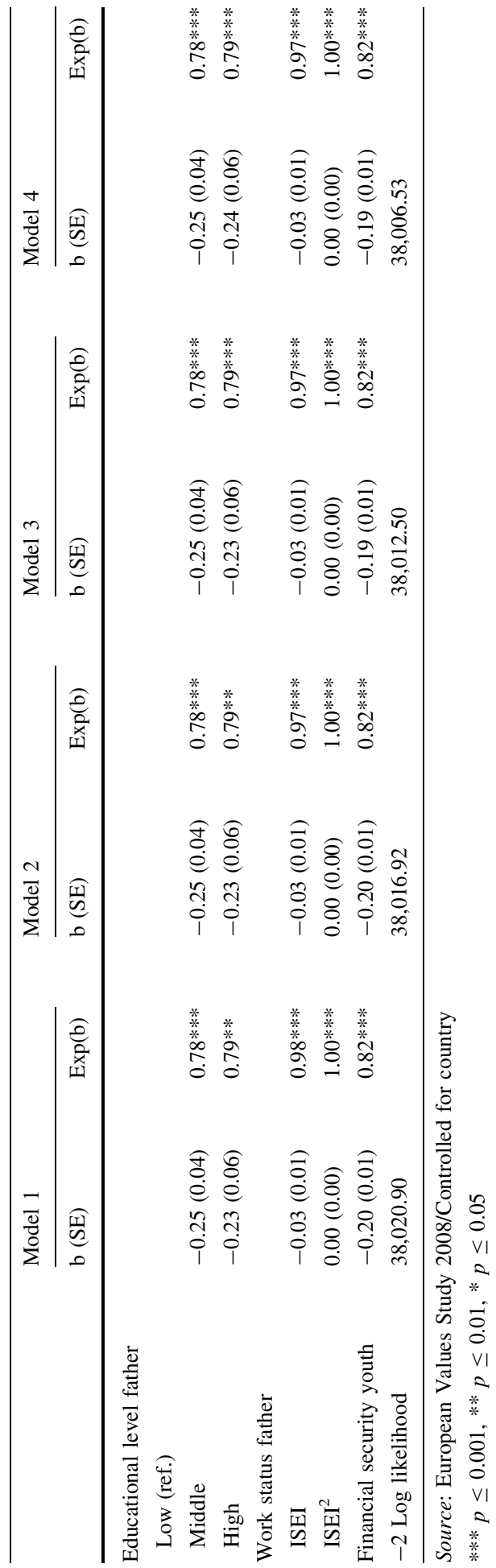


interaction terms in our models with gender and examine whether the association between bereavement and happiness is stronger for women than for men.

In Table 3 we examine the relationship between parental death and the likelihood of feeling unhappy. In all four models we control for people's gender, age, and the socioeconomic status of the family of origin. Men and women do not significantly differ from each other with regard to the likelihood of feeling unhappy. Older people are more likely to feel unhappy than younger people. For people in their fifties the odds of feeling unhappy are $58 \%$ higher as compared to people younger than $30((1.58-1) \times 100){ }^{3}$ Furthermore, our findings indicate that the socioeconomic status of the family of origin is negatively related to the likelihood of feeling unhappy. The odds of feeling unhappy are highest for people whose father completed a low level education and had a low work status, and for people who grew up with little financial security.

In model 1 of Table 3 we include the dichotomous variables regarding parental death together with the control variables. The odds of feeling unhappy are respectively 17 and 19 percent higher for people who lost their father or mother as compared to those who have not experienced this loss. In this model, the effects of death of the father and death of the mother on the likelihood of feeling unhappy appear to be equally strong. This contradicts hypothesis $3 c$ which states that the death of the mother will have a stronger influence on the happiness of adult children than the death of the father.

In the second model of Table 3, we replace the dichotomous variables regarding parental death with dummy-variables that relate to the duration of the loss. Our expectation is that parental death has a stronger impact on people's happiness when it occurred more recently. However, our findings in model 2 do not support this expectation. When we compare the effect of the dichotomous variables in model 1 with the effects of the dummyvariables in model 2, they turn out to be quite similar. Additional analyses, in which we alternately change the reference category of the dummy-variables, demonstrate that the effects of the dummy-categories regarding death of the father/mother do not significantly differ from each other. The odds of feeling unhappy are equally strong for people who lost their father/mother $<2$ years ago as for people who lost their father/mother more than 10 years ago.

Model 3 of Table 3 demonstrates the association between the age at which the death of a parent occurred and the likelihood of feeling unhappy. In accordance with the life span hypothesis, the death of the father during youth negatively affects people's happiness in adult life. For people whose father died in their youth, the odds of feeling unhappy are $27 \%$ higher than for people whose father is still alive. The death of the father has a smaller impact on the likelihood of feeling unhappy when this occurs after the age of 21. Against our expectation, the death of the mother in people's youth is not significantly related to the likelihood of feeling unhappy in adult life. However, the death of the mother is positively related to feeling unhappy when this occurred in people's adult life. The odds of feeling unhappy are respectively 24 and $12 \%$ higher for people who lost their mother between 22 and 40 years old and after the age of 40 as compared to people whose mother is still alive. However, additional analyses (in which we alternately change the reference category) reveal that the effects of the dummy-categories regarding maternal death do not significantly differ from each other.

\footnotetext{
${ }^{3} \operatorname{Exp}(\mathrm{B})$ is the change in the odds of being unhappy associated with a 1 unit change in the predictor variable. In the case of a categorical variable, it indicates the difference in odds with regard to the reference category.
} 
In model 4, we try to detach the effect of duration of the loss from the effect of the age at which the loss occurred by combining both variables into a newly constructed variable. ${ }^{4}$ On the basis of our results, we can conclude that the death of the father in people's youth has a negative impact on happiness in adult life. Although we find this effect for both the people who recently lost their father ( $<5$ years ago) and the people whose father died some time ago, it is stronger for the former group. The effects of the other dummy-categories regarding paternal death do not significantly differ from each other. Regarding maternal death, the results are less clear. In the case of recent death $(<5$ years ago), the logit for people who lost their mother during youth is strongly positive (significant at an alpha of 0.10). The odds of feeling unhappy are $84 \%$ higher for people who lost their mother recently during their youth as compared to people whose mother is still alive. Furthermore, our findings indicate that the death of the mother is positively related to the likelihood of feeling unhappy when this occurred when people were between 22 and 40 years old. However, additional analyses reveal that, due to large standard errors, the effects of the dummy-categories regarding maternal death do not significantly differ from each other.

Summarizing, we can conclude that our results regarding parental death do not support the set-point hypothesis, as the impact of parental death on happiness does not strongly fluctuate with the duration of the loss. However, we do find that losing a parent on a relatively young age has a stronger effect on happiness when this occurred recently $(<5$ years ago). The resources hypothesis is partially supported by our findings regarding parental death. The death of a parent can have a long term effect on people's feelings of happiness, but only when the loss occurred on a relatively young age. This offers some support for the life span hypothesis, which states that the negative impact of parental death on people's SWB decreases across the life course. However, it should be noted that our results regarding parental death are sometimes inconclusive and do not provide support for one specific hypothesis.

Table 4 shows the findings of our second analysis on the association between experiencing the death of a child and being unhappy. In all four models of Table 4, we include several control variables to minimize the possibility of a spurious relationship. The likelihood of feeling unhappy increases with age. However, after the age of 70, this likelihood appears to be relatively stable. Furthermore, our findings demonstrate that people's socioeconomic status is related to their SWB. People with lower levels of income and education have a heightened probability of being unhappy. People with a higher occupational status are less likely to feel unhappy, but this effect appears to be curvilinear.

In the first model of Table 4 we only include the dichotomous variable regarding the death of a child. We see that the odds of feeling unhappy are $60 \%$ higher for people who lost a child compared to people without this experience. In accordance with our expectation, the association between the death of a child and happiness seems to be stronger than the association between parental death and happiness.

The duration of the loss is included in the second model of Table 4. The death of a child is positively related to the likelihood of feeling unhappy on both the short-term and longterm. However, we do find that the effect of the death of a child on the short term $(<5$ years ago) is substantial stronger (more than twice as large) than the effect on the long-term ( $>10$ years ago). For people who lost a child less than 5 years ago the odds of feeling unhappy is 2.3 times higher compared to people who didn't lost their child.

\footnotetext{
4 In additional analyses we excluded age as a predictor variable and calculated Model 4 for different age groups. The results prove to be quite similar.
} 


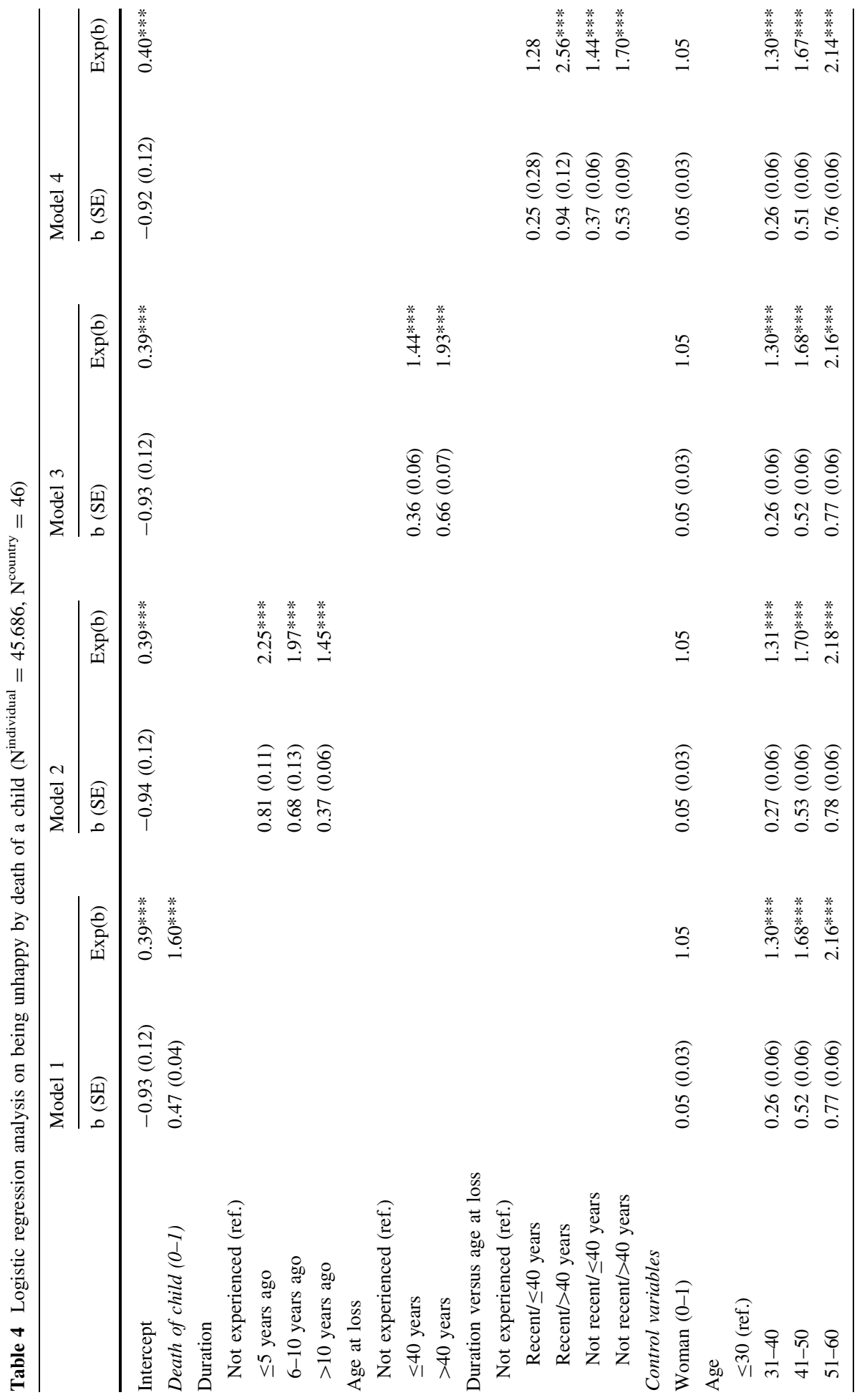




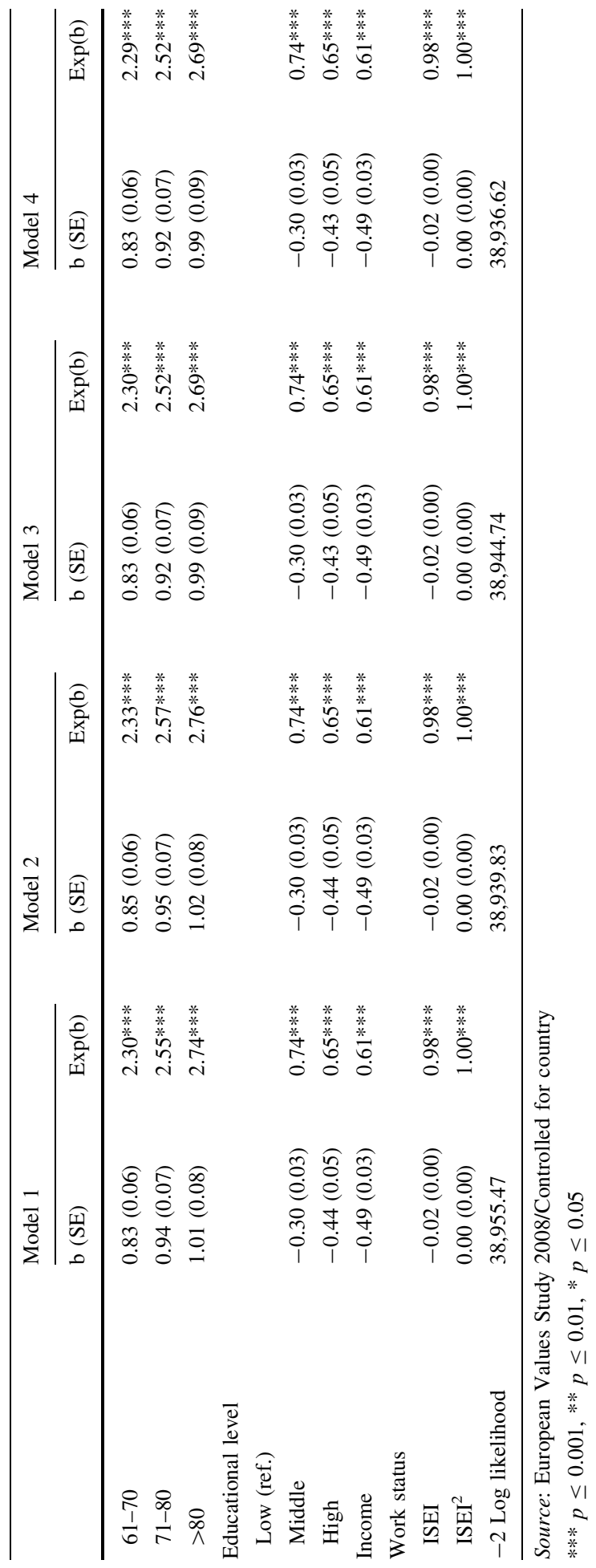


Table 5 The impact of bereavement on being unhappy moderated by gender

\begin{tabular}{lcr}
\hline & $\mathrm{B}$ & $\mathrm{SE}$ \\
\hline Death of father (0-1) & $0.17 * * *$ & 0.05 \\
Woman* & -0.03 & 0.06 \\
Death of mother (0-1) & $0.12 * *$ & 0.05 \\
Woman* & 0.10 & 0.07 \\
$\mathrm{~N}^{\text {individual }}=48.829, \mathrm{~N}^{\text {country }}=46$ & & $0.37 * * *$ \\
Death of child $(0-1)^{\text {Woman }}$ & 0.16 & 0.09 \\
$\mathrm{~N}^{\text {individual }}=45.686, \mathrm{~N}^{\text {country }}=46$ & & 0.09
\end{tabular}

Source: European Values Study 2008/controlled for country controlled for all the variables in Tables 3 and 4 $* * * p \leq 0.001, * * p \leq 0.01, * p \leq 0.05$

Model 3 of Table 4 focuses on the age at which parents lost their child. Our findings demonstrate that the association between parental bereavement and feeling unhappy is substantially stronger for people over 40 than for people younger than 40 . A possible explanation for this finding is that a substantial part of the people who lost their child before their fortieth lost a child in pregnancy, a newborn child or a very young child with whom there was little time to bond. However, we are not able to test this explanation as we have no information about the age of the deceased child. The odds of feeling unhappy are almost twice as large for people who lost a child after the age of forty than for people who have not lost a child.

Model 4, where we have plotted the duration of the loss against the age at which the loss occurred, summarizes our findings with regard to parental bereavement. Our findings offer indirect support for the argument that losing a newborn or young child is less traumatic for parents than losing an adult child (Pudrovska 2009; Wijngaards-de Meij et al. 2005), especially in the case of recent loss. The death of a child is negatively related to happiness, both on the short-term and long-term. However, in the case of losing a child after the age of forty, the association appears to be considerably stronger when the loss occurred recently. This does not seem to be the case when it comes to losing a child before the age of forty. In general, our research findings contradict the set-point hypothesis which states that the death of a child only has a temporary effect on people's feelings of happiness. The resources hypothesis is for the largest part supported by our findings.

In Table 5 we test to what extent the association between bereavement and being unhappy differs for men and women. We control for all the variables as included in Tables 3 and 4, but only the main effects of the bereavement variables and the interaction effects with gender are shown in Table 5.

For each type of loss we alternately calculated interaction effects between the bereavement variables and gender. The results show that there are hardly gender differences in the association between parental death and feeling unhappy. Men and woman are equally suffering from the loss of their father or mother. As gender differences in the association between parental death and feeling unhappy are non-existent, we have to reject both the gender role hypothesis and the emotional coping hypothesis. We also have to reject the same-sex parent hypothesis, as our findings do not support the expectation that the death of the same-sex parent has the strongest influence on the SWB of their children. 
At first, Table 5 seems to suggest that the death of a child has a stronger impact on the well-being of women than of men. However, the interaction effect between parental bereavement and gender is not significant. Therefore, we have to reject both the gender role hypothesis and the emotional coping hypothesis. The death of a child results in an increase in the likelihood of feeling unhappy, equally to men and women. ${ }^{5}$

\section{Conclusion and Discussion}

Our overarching research question reads: To what extent is there an association between bereavement and SWB, and how does it differ (a) with the duration of the loss, (b) across the life-course, (c) between men and women?

Our research findings demonstrate that there is indeed a positive association between bereavement and being unhappy (Stroebe et al. 2007). People who lost their father, mother or child are more likely to feel unhappy than people without this experience. Moreover, our findings demonstrate that the association between the death of a child and being unhappy is substantially stronger than the association between the death of a parent and being unhappy. This supports the argument in the literature that people have large difficulties in overcoming the death of their child as parents are not supposed to survive their children (Pudrovska 2009).

According to set-point theory, external conditions are expected to only have a shortterm influence on SWB, whereas affective theories predict that some conditions also can have a long-term impact. In this study, we therefore tested the concept of 'lasting grief'. Regarding parental death, our findings suggest that the impact of the loss on SWB does not strongly decrease with the duration of loss. The association between parental death and being unhappy seems to be equally strong for people who lost their father or mother quite recently as for people who lost their parent more than 10 years ago. However, in the case of losing a parent during youth, recent loss seems to have more severe consequences for people's SWB. In the case of parental bereavement we do find that the association between the death of a child and feeling unhappy decreases with the duration of the loss. However, it should be noted that bereavement is not only related with SWB on the short term. Ten years after the death of a parent or child, bereaved people are still unhappier than people who have not experienced the death their relative. The assumption of set-point theory, that major life events only have a temporary impact on SWB (Brickman and Campbell 1971; Lykken and Tellegen 1996), is not supported by our data.

In response to our second sub-question we can conclude that the association between bereavement and SWB strongly differs across the life-course. We might even conclude that the age at which the loss occurred is more decisive for the strength of the association between bereavement and SWB than the duration of the loss. We found for example that the death of a parent during childhood or young adulthood has a negative impact on people's SWB, both on the short-term and long-term. This supports the argument that the death of a parent later in life is less traumatic for the adult chid than in an earlier stage in life, as parental death becomes more natural and expected (Rostila and Saarela 2011). Losing a child has a strong negative impact on people's SWB at all ages. However, grief reactions appear to be less severe for parents who lost a child on a relatively young age

\footnotetext{
5 Also when we take into account the duration of the loss and the age at which the loss occurred, the interaction-terms between the bereavement variables and gender appear to be non-significant (results of these additional analyses can be obtained from the corresponding author).
} 
(before the age of 40). This seems to suggest that losing an adult child has a stronger negative impact on people's SWB than losing a younger child (Wijngaards-de Meij et al. 2005). A possible explanation for this finding is that people who lost a child on a relatively young age in most cases lost a child during pregnancy or a newborn or very young child. Because we do not have information about the age of the deceased child, we were not able to test this hypothesis.

Our third sub-question relates to possible gender differences in the association between bereavement and SWB. On the basis of the gender role perspective, we expected women to display more grief reactions after the death of a relative than men, as their lives are more intertwined with that of their parents and children. However, based on the assumption that women are better able to cope with the death of a relative, we expected the opposite. Our findings support neither of these expectations. The association between bereavement and happiness is equally strong for men and women. Also the hypothesis that the death of the same-sex parent has the strongest impact on the SWB of adult children (Marks et al. 2007) is not supported by the results.

Finally, we want to discuss two limitations of our study in relation to our conclusions, and to make a recommendation for further research. A first limitation of this study design is that we do not have information about the deceased parent or child. We only know at what age a person has experienced the death of a parent or child, and not the age at which this close relative died. Since the age of parents and children are strongly related, our results indirectly show that losing a younger parent has a stronger impact on SWB than losing an elderly parent. For parental bereavement this appears to be the opposite: Losing a young child has less severe consequences for SWB than losing an adult child. Of course it would have been better if we had information about the age of the deceased parent/child. We could than have tested our hypothesis that losing a young child has more severe consequences for SWB than losing an adult child, because in most cases it will involve losing a newborn.

A second limitation is that we use cross-sectional data for testing our hypotheses about the association between bereavement and SWB, whereas using panel data would have been more appropriate. With cross-sectional data, the concept of adaptation is difficult to measure. The question 'do people eventually return to their set-points?' remains unanswered. However, on the basis of cross-sectional data from the European Values Study, we demonstrated that people who lost a parent or child are less happy than people who have not experienced this loss. This relationship also exists in the case that the loss occurred more than 10 years ago. Since we have controlled for all the relevant variables we could think of, the possibility of a spurious relationship is not obvious here. In addition, an important advantage of using the European Values study (instead of a smaller-scale panel study) is that we have a large dataset to our disposal which allowed us to extensively examine the association between bereavement and SWB.

A recommendation for future research is to study cross-national variations in the association between bereavement and SWB. Contextual factors (cultural or structural in nature) may buffer consequences of bereavement. In this study the analysis of country differences in the association between bereavement and SWB is beyond our scope, although we think that these country differences deserve attention.

Open Access This article is distributed under the terms of the Creative Commons Attribution 4.0 International License (http://creativecommons.org/licenses/by/4.0/), which permits unrestricted use, distribution, and reproduction in any medium, provided you give appropriate credit to the original author(s) and the source, provide a link to the Creative Commons license, and indicate if changes were made. 


\section{References}

Ballas, D., \& Dorling, D. (2007). Measuring the impact of major life events upon happiness. International Journal of Epidemiology, 36(3), 1244-1252.

Baumeister, R. F. (2002). Yielding to temptation: Self-control failure, impulsive purchasing, and consumer behavior. Journal of Consumer Research, 28(4), 670-676.

Bielby, D. D., \& Bielby, W. T. (1988). She works hard for the money: Household responsibilities and the allocation of work effort. American Journal of Sociology, 93(5), 1031-1059.

Bifulco, A., Harris, T., \& Brown, G. W. (1992). Mourning or early inadequate care? Reexamining the relationship of maternal loss in childhood with adult depression and anxiety. Development and Psychopathology, 4(3), 433-449.

Boerner, K., Wortman, C. B., \& Bonanno, G. A. (2005). Resilient or at risk? A 4-year study of older adults who initially showed high or low distress following conjugal loss. The Journals of Gerontology Series B: Psychological Sciences and Social Sciences, 60(2), 67-73.

Brickman, P. D., \& Campbell, D. T. (1971). Hedonic relativism and planning the good society. In M. H. Appley (Ed.), Adaptation level theory. New York: Academic Press.

Clark, A. E., Diener, E., Georgellis, Y., \& Lucas, R. E. (2008). Lags and leads in life satisfaction: A test of the baseline hypothesis. The Economic Journal, 118, 222-243.

Cooney, T. M., \& Uhlenberg, P. (1992). Support from parents over the life course: The adult child's perspective. Social Forces, 71(1), 63-84.

Costa, P. T., \& McCrae, R. R. (1980). Influences of extraversion and neuroticism on subjective well-being. Journal of Personality and Social Psychology, 38, 668-678.

Craig, L. (2006). Does father care mean fathers share? A comparison of how mothers and fathers in intact families spend time with children. Gender \& Society, 20(2), 259-281.

Diener, E., \& Fujita, F. (1995). Recources, personal strivings, and subjective well-being: A nomothetic and idiographic approach. Journal of Personality and Social Psychology, 68, 926-935.

Diener, E., Sandvik, E., \& Pavot, W. (1991). Happiness is the frequency, not the intentsity, of positive versus negative affect. In F. Strack, M. Argyle, \& N. Schwarz (Eds.), Subjective well-being: An interdisciplinary perspective. Elmsford, NY: Pergamon Press.

Diener, E., Lucas, R. E., \& Oishi, S. (2002). Subjective well-being. Handbook of Positive Psychology, 63-73.

Diener, E., Lucas, R. E., \& Scollon, C. N. (2006). Beyond the hedonic treadmill: Revising the adaptation theory of well-being. American Psychologist, 61(4), 305-314.

Easterlin, R. A. (2005). Building a better theory of well-being. In P. A. David \& M. W. Reder (Eds.), Economics and hapiness: Framing the analysis. Oxford: Oxford University Press.

EVS. (2010). European values study 2008. GESIS Data Archive, Cologne, Germany, ZA4800 Data File Version 3.0.0, doi:10.4232/1.11005.

Fujita, F., \& Diener, E. (2005). Life satisfaction set point: Stability and change. Journal of Personality and Social Psychology, 88(1), 158-164.

Ganzeboom, H. B., De Graaf, P. M., \& Treiman, D. J. (1992). A standard international socio-economic index of occupational status. Social Science Research, 21(1), 1-56.

Gutek, B. A., Searle, S., \& Klepa, L. (1991). Rational versus gender role explanations for work-family conflict. Journal of Applied Psychology, 76(4), 560-568.

Heady, B. (2010). The set point theory of well-being has serious flaws: On the eve of a scientific revolution? Social Indicators Research, 97(1), 7-21.

Heady, B. W., \& Wearing, A. J. (1989). Personality, life events, and subjective well-being: Toward a dynamic equilibrium model. Journal of Personality and Social Psychology, 57(4), 731-739.

Heady, B. W., \& Wearing, A. J. (1992). Understanding happiness: A theory of subjective well-being. Melbourne: Longman Cheshire.

Kalpakjian, C. Z., Houljhan, B., Meade, M. A., Karana-Zebari, D., Heinemann, A. W., Dijkers, M. P., et al. (2011). Marital status, marital transitions, well-being, and spinal cord injury: An examination of the effects of sex and time. Archives of Physical Medicine and Rehabilitation, 92(3), 433-440.

Kersting, A., Brähler, E., Glaesmer, H., \& Wagner, B. (2011). Prevalence of complicated grief in a representative population-based sample. Journal of Affective Disorders, 131, 339-343.

Li, J., Precht, D. H., Mortensen, P. B., \& Olsen, J. (2003). Mortality in parents after death of a child in Denmark: A nationwide follow-up study. The lancet, 361, 363-367.

Li, J., Laursen, T. M., Precht, D. H., Olsen, J., \& Mortensen, P. B. (2005). Hospitalization for mental illness among parents after the death of a child. New England Journal of Medicine, 352(12), 1190-1196.

Lindenberg, S. (1986). The paradox of privatization in consumption. In A. Diekmann \& P. Mitter (Eds.), Paradoxical effects of social behavior. Physica: Heidelberg/Wien. 
Loscocco, K., \& Spitze, G. (2007). Gender patterns in provider role attitudes and behavior. Journal of Family Issues, 28(7), 934-954.

Lucas, R. E. (2007). Adaptation and the set-point model of subjective well-being. Does happiness change after major life events? Current Directions in Psychological Science, 16(2), 75-79.

Lucas, R. E., Clark, A. E., Georgellis, Y., \& Diener, E. (2003). Reexamining adaptation and the set point model of happiness: Reactions to changes in marital status. Journal of Personality and Social Psychology, 84(3), 527-539.

Luhmann, M., Hofmann, W., Eid, M., \& Lucas, R. E. (2012). Subjective well-being and adaptation to live events: A meta-analysis. Journal of Personality and Social Psychology, 102(3), 592-615.

Lykken, D. (1999). Happiness: What studies on twins show us about nature, nurture and the happiness setpoint. New York: Golden Books.

Lykken, D., \& Tellegen, A. (1996). Happiness is a stochastic phenomenon. Psychological Science, 7, 186-189.

Maier, E. H., \& Lachman, M. E. (2000). Consequences of early parental loss and seperation for health and well-being in midlife. International Journal of Behavioral Development, 24(2), 183-189.

Mandemakers, J. J. (2011). Socio-economic differentials in the impact of life course transitions on wellbeing. Dissertation, Tilburg University.

Marks, N. F., Jun, H., \& Song, J. (2007). Death of parents and adult psychological and physical well-being. A prospective US National Study. Journal of Family Issues, 28, 1611-1638.

Middleton, W., Burnett, P., Raphael, B., \& Martinek, N. (1996). The bereavement response: A cluster analysis. The British Journal of Psychiatry, 169(2), 167-171.

Middleton, W., Raphael, B., Burnett, P., \& Martinek, N. (1998). A longitudinal study comparing bereavement phenomena in recently bereaved spouses, adult children and parents. Australasian Psychiatry, 32(2), 235-241.

Ormel, J., Lindenberg, S., Steverink, N., \& Verbrugge, L. M. (1999). Subjective well-being and social production functions. Social Indicators Research, 46(1), 61-90.

Oswald, A. J., \& Powdthavee, N. (2008). Death, happiness, and the calculations of compensatory damages. The Journal of Legal Studies, 37(2), 217-251.

Pinquart, M., \& Sörensen, S. (2007). Correlates of physical health of informal caregivers: A meta-analysis. The Journals of Gerontology Series B: Psychological Sciences and Social Sciences, 62(2), 126-137.

Pudrovska, T. (2009). Parenthood, stress, and mental health in late midlife and early old age. International Journal of Aging and Human Development, 68(2), 127-147.

Rogers, C. H., Floyd, F. J., Seltzer, M. M., Greenberg, J., \& Hong, J. (2008). Long-term effects o the death of a child on parents' adjustment in midlife. Journal of Family Psychology, 22(2), 203-211.

Rosenthal, C. J. (1985). Kinkeeping in the familial division of labor. Journal of Marriage and the Family, 47(4), 965-974.

Rossi, A. S., \& Rossi, P. H. (1990). Of human bonding: Parent-child relations across the life course. New York: Aldine de Gruyter.

Rostila, M., \& Saarela, J. M. (2011). Time does not heal all wounds: Mortality following the death of a parent. Journal of Marriage and Family, 73, 236-249.

Rostila, M., Saarela, J., \& Kawachi, I. (2012). Mortality in parents following the death of a child: A nationwide follow-up study from Sweden. Journal of Epidemiology and Community Health, 66(10), 927-933.

Sanders, C. M. (1979). A comparison of adult bereavement in the death of a spouse, child, and parent. Journal of Death and Dying, 10(4), 303-322.

Schulz, R., \& Sherwood, P. R. (2008). Physical and mental health effects of family caregiving. The American journal of nursing, 108, 23-27.

Schulz, R., Mendelsohn, A. B., Haley, W. E., Mahoney, D., Allen, R. S., Zhang, S., \& Belle, S. H. (2003). End-of-life care and the effects of bereavement on family caregivers of persons with dementia. New England Journal of Medicine, 349(20), 1936-1942.

Song, J., Floyd, F. J., Seltzer, M. M., Greenberg, J. S., \& Hong, J. (2010). Long-term effects of child death on parents' health-related quality of life: A dyadic analysis. Family Relations, 59, 269-282.

Specht, J., Egloff, B., \& Schmukle, S. C. (2011). The benefits of believing in chance or fate: External locus of control as a protective factor for coping with the death of a spouse. Social Psychological and Personality Science, 2(2), 132-137.

Stroebe, M. (2001). Gender differences in adjustment to bereavement: An empirical and theoretical review. Review of general psychology, 5(1), 62-83.

Stroebe, M., \& Stroebe, W. (1983). Who suffers more? Sex differences in health risks of the widowed. Psychological Bulletin, 93(2), 279-301.

Stroebe, M., Schut, H., \& Stroebe, W. (2007). Health outcomes of bereavement. Lancet, 370, 1960-1973. 
Umberson, D., Wortman, C. B., \& Kessler, R. C. (1992). Widowhood and depression: Explaining long-term gender differences in vulnerability. Journal of Health and Social Behavior, 33(1), 10-24.

Umberson, D., Chen, M. D., House, J. S., Hopkins, K., \& Slaten, E. (1996). The effect of social relationships on psychological well-being: Are men and women really so different? American Sociological Review, 61(5), 837-857.

Umberson, D., Pudrovska, T., \& Reczek, C. (2010). Parenthood, childlessness and well-being: A life course perspective. Journal of Marriage and Family, 72, 612-629.

Veenhoven, R. (1993). Happiness as an indicator in social policy evolution: Some objections considered. In Mesman Schulz et al. (Eds.), Between sociology and social practice (pp. 195-206). Nijmegen: ITS.

Veenhoven, R. (1994). Is happiness a trait? Test of the theory that a better society does not make people any happier. Social Indicators Research, 32(2), 101-160.

Veenhoven, R. (2009). How do we assess how happy we are? Tenets, implications and tenability of three theories. In A. K. Dutt \& B. Radcliff (Eds.), Happiness, economics and politics: Towards a multidisciplinary approach (Vol. 3, pp. 45-69). Cheltenham: Edward Elger Publishers.

Waite, L., Luo, Y., \& Lewin, A. C. (2009). Marital happiness and marital stability: Consequences for psychological well-being. Social Science Research, 38(1), 201-212.

Wall, G., \& Arnold, S. (2007). How involved is involved fathering? An exploratoin of the contemporary culture of fatherhood. Gender \& Society, 21(4), 508-527.

Wijngaards-de Meij, L., Stroebe, M., Schut, H., Stroebe, W., van den Bout, J., van der Heijden, P., \& Dijkstra, I. (2005). Couples at risk following the death of their child: Predictors of griep versus depression. Journal of Consulting and Clinical Psychology, 73(4), 617-623. 